\title{
SERAPAN KARBON DIOKSIDA TUMBUHAN ULAYAT UNTUK RUANG TERBUKA HIJAU DI KOTA PALANGKA RAYA
}

\author{
Yetrie Ludang \\ Program Studi Kehutanan, Universitas Palangka Raya, Indonesia \\ Email :yludang@yahoo.com
}

\begin{abstract}
Abstrak
Perkembangan pembangunan dan perekonomian Kota Palangka Raya semakin pesat yang berdampak negatif terhadap tutupan lahan bervegetasi, berkurangnya ketersediaan oksigen dan meningkatnya emisi gas $\mathrm{CO}_{2}$. Upaya untuk menekan dampak negatif tersebut salah satunya adalah memperbanyak RTH dengan pemilihan jenis tumbuhan yang tepat. Pemilihan jenis tumbuhan RTH dilihat dari sisi pengetahuan ilmiah sudah banyak dilakukan, sedangkan penelitian yang memadukan pengetahuan ilmiah dan ulayat belum banyak dilakukan. Penelitian ini bertujuan untuk memperoleh bukti keilmuan mengenai jenis tumbuhan ulayat sebagai tumbuhan RTH terkait kemampuannya dalam menyerap $\mathrm{CO}_{2}$ dari atmosfir. Penentuan jenis tumbuhan ulayat dilakukan dengan metode wawancara langsung terhadap responden Suku Dayak asli. Pengukuran serapan $\mathrm{CO}_{2}$ tumbuhan menggunakan metode sungkup berukuran $50 \mathrm{~cm}$ x $50 \mathrm{~cm}$ x $30 \mathrm{~cm}$. Analisis konsentrasi $\mathrm{CO}_{2}$ menggunakan Gas Cromatography. Serapan $\mathrm{CO}_{2}$ akan tumbuhan diukur pada periode waktu pengukuran pukul 06.00, 09.00, 12.00 dan 15.00 WIB dengan interval waktu pengambilan gas $\mathrm{CO}_{2}$ pada menit ke 5, 10, 15, 20, 25 dan 30. Pengukuran berat kering, persen dan karbon organik tumbuhan ulayat menggunakan metode gravimetri. Berdasarkan hasil penelitian bahwa jenis tumbuhan yang memiliki nilai-nilai kesakralan/ ulayat bagi masyarakat Suku Dayak Kota Palangka Raya adalah Pinang Merah (Cyrtostachys lakka), Serai (Cymbopogon citratus), Kenanga (Canangium odoratum), dan Thorms. Kemampuan serapan $\mathrm{CO}_{2}$ tumbuhan Pinang Merah sebesar $1,37 \mathrm{mg} / \mathrm{m}^{2} /$ menit, Serai $1,35 \mathrm{mg} / \mathrm{m}^{2} / \mathrm{menit}$ dan Kenanga $1,22 \mathrm{mg} / \mathrm{m}^{2} / \mathrm{menit}$. Tumbuhan ulayat dalam penelitian ini merupakan tumbuhan yang memiliki fungsi utama serta memiliki kemampuan serapan $\mathrm{CO}_{2}$ tinggi yang mampu menekan peningkatan gas $\mathrm{CO}_{2}$ di atmosfir.
\end{abstract}

Kata kunci : ruang terbuka hijau, serapan $\mathrm{CO}_{2}$, tumbuhan, tumbuhan ulayat

\begin{abstract}
Construction and economic development of Palangkaraya more rapidly that negatively impact vegetated land cover, reduced availability of oxygen and increasing $\mathrm{CO}_{2}$ emissions. Effort to reduce the negative impact of one of them is to multiply the green space with the selection of appropriate plant species. Selection of plant species of green space in terms of scientific knowledge has been done, while research that combines science and indigenous knowledge has not been done. This study aimed to obtain scientific evidence on the types of indigenous plants as herbs associated $\mathrm{RTH}$ ability to absorb $\mathrm{CO}_{2}$ from the atmosphere. Determination of plant species indigenous to do with the method of direct interviews with respondents indigenous Dayak. Measurement of $\mathrm{CO}_{2}$ uptake of plants using methods lid measuring $50 \mathrm{~cm} \times 50 \mathrm{~cm} \times 30$ cm. $\mathrm{CO}_{2}$ concentration analysis using Gas Cromatography. Seedling plant $\mathrm{CO}_{2}$ uptake was measured at measurement time period 06:00,09:00, 12:00 and 15:00 pm with $\mathrm{CO}_{2}$ gas capture time interval in minutes to 5, 10, 15, 20, 25 and 30. Measurement of dry weight, percent organic carbon plant and customary use gravimetric method. Based on the research that the type of plants that have the values of the sanctity/ customary for people Dayak city of Palangkaraya is Pinang Merah, Lemongrass, and Kenanga, and Thorms. $\mathrm{CO}_{2}$ uptake ability of plants Red Pinang by $1.37 \mathrm{mg} / \mathrm{m}^{2} / \mathrm{min}$, Serai $1.35 \mathrm{mg} / \mathrm{m}^{2} / \mathrm{min}$ and Kenanga 1.22 $\mathrm{mg} / \mathrm{m}^{2} / \mathrm{min}$. Plants customary in this study is a plant whose main function and additional functions and has a high $\mathrm{CO}_{2}$ absorption capability that is able to suppress the increase of $\mathrm{CO}_{2}$ in the atmosphere.
\end{abstract}

Keywords: urban green space, carbon dioksida, plants, plant indigenous 


\section{PENDAHULUAN}

Kota Palangka Raya sebagai ibukota Provinsi Kalimantan Tengah memiliki luas wilayah $2.678,51 \mathrm{~km}^{2}$ atau 267.851 hektar dengan jumlah penduduk pada tahun 2013 sebanyak 244.500 jiwa meningkat dari tahun 2012 sebesar $6,49 \%$ dengan kepadatan penduduk $91 \mathrm{jiwa} / \mathrm{km}^{2}$ (BPS Kota Palangka Raya, 2014). Perkembangan pembangunan dan perekonomian Kota Palangka Raya yang semakin pesat memberikan dampak positif terhadap peningkatan kesejahteraan masyarakat. Namun disisi lain, perkembangan pembangunan dan perekonomian yang ditandai dengan semakin banyaknya pemukiman baru, pertokoan, sarana transportasi dan sarana penunjang lainnya memiliki dampak negatif terhadap tekanan dan kualitas lingkungannya. Dampak negatif tersebut diantaranya, semakin berkurangnya tutupan lahan yang bervegetasi sehingga berpengaruh terhadap ketersediaan oksigen dan semakin meningkatnya emisi gas karbon dioksida $\left(\mathrm{CO}_{2}\right)$ yang dihasilkan. Upaya untuk menekan dampak negatif tersebut salah satunya adalah memperbanyak Ruang Terbuka Hijau (RTH) di Kota Palangka Raya dengan pemilihan jenis tumbuhan yang tepat.

Pemilihan jenis tumbuhan RTH dilihat berdasarkan pengetahuan ilmiah diantaranya : cocok dengan kondisi tanah, berfungsi sebagai peneduh dan pelindung, memiliki nilai estetika, memiliki serapan $\mathrm{CO}_{2}$ tinggi. Penelitian tentang pemilihan jenis tumbuhan untuk RTH dilihat dari sisi pengetahuan ilmiah sudah banyak dilakukan. Sedangkan penelitian yang memadukan pengetahuan ilmiah dan ulayat belum banyak dilakukan. Pengetahuan ulayat merupakan basis dari pembangunan nasional yang berkelanjutan karena memasukkan pengalaman, keahlian dan wawasan yang dimiliki oleh masyarakat setempat bahwa pengembangan keilmuan dalam menetapkan RTH tidak semata-mata oleh tumbuhan tetapi juga oleh budaya/kultur setempat (United Nation Enviromental Programe, 2009).

Sehubungan dengan pradigma di atas, maka penelitian ini dilakukan untuk menghasilkan sinergi antara pengetahuan ilmiah dan ulayat yang berlaku di masyarakat Suku Dayak Kota Palangka Raya, dalam hal pemilihan jenis tumbuhan RTH. Tujuan penelitian adalah memperoleh bukti keilmuan mengenai jenis tumbuhan ulayat sebagai tumbuhan RTH terkait kemampuannya dalam menyerap $\mathrm{CO}_{2}$ dari atmosfir.

\section{METODE PENELITIAN}

\section{Lokasi dan waktu}

Penelitian dilaksanakan di Kota Palangka Raya Provinsi Kalimantan Tengah dan di Balai Penelitian Lingkungan Pertanian Jakenan Pati, Jawa Tengah serta di laboratorium jurusan/PS Kehutanan Fakultas Pertanian Universitas Palangka Raya. Pelaksanaan penelitian dilakukan pada bulan Maret - Mei 2013.

\section{Bahan dan alat}

Bahan yang digunakan terdiri dari jenis tumbuhan ulayat berumur 2-4 bulan (tingkat pertumbuhan anakan), pasir, kertas koran, air dan media tanam berupa campuran tanah dan serbuk kayu serta sedikit pupuk kandang sapi dilengkapi polybag berdiameter $22,5 \mathrm{~cm}$ dengan tinggi $9,5 \mathrm{~cm}$.

Alat yang digunakan adalah sungkup sebanyak 4 unit berukuran $50 \mathrm{~cm} \times 50 \mathrm{~cm} \times 30 \mathrm{~cm}$ dilengkapi baterai, termometer, kipas angin dan septum (karet penutup lubang sungkup), Gas Cromatography, syringe yang dilengkapi pembungkus kertas perak dan karet padat penutup syringe, kertas label, kaliper, meteran, penggaris $50 \mathrm{~cm}$, oven, desikator, tanur pengabuan, cawan pengabuan, ember, keranjang plastik kecil, karet gelang, kantong kertas, stereoform, stopwatch, isolasi, kamera, gunting, bedengan berukuran $4 \mathrm{~m} \times 1 \mathrm{~m}$, timbangan analitik, blender serta alat tulis menulis.

\section{Prosedur penelitian}

\section{Penentuan jenis tumbuhan ulayat}

Masyarakat Kota Palangka Raya sebagian besar didominasi oleh Suku Dayak, merupakan penduduk asli setempat. Untuk menentukan 
jenis tumbuhan ulayat dilakukan dengan metode wawancara langsung terhadap responden Suku Dayak asli tidak bercampur dengan suku lain yang hidup 2-3 generasi di 5 Kecamatan Kota Palangka Raya, yaitu Kecamatan Pahandut, Jekan Raya, Bukit Batu, Sebangau dan Rakumpit. Berdasarkan hasil wawancara untuk jenis tumbuhan ulayat diantaranya adalah Pinang Merah (Cyrtostachys lakka Becc.), Serai (Cymbopogon citratus) dan Kenanga (Canangium odoratum (Lamk.) Hook. dan Thorms. (Lat.)).

\section{Pengukuran serapan karbon dioksida tumbuhan ulayat}

Metode pengukuran serapan $\mathrm{CO}_{2}$ tumbuhan menggunakan metode sungkup (chamber) berukuran $50 \mathrm{~cm} \times 50 \mathrm{~cm} \times 50 \mathrm{~cm}$. Jumlah sungkup yang digunakan sebanyak 4 unit terdiri dari 3 unit untuk tumbuhan ulayat dan 1 unit untuk kontrol (tanpa tumbuhan). Pengukuran serapan $\mathrm{CO}_{2}$ dimulai dengan meletakkan masing-masing tumbuhan di atas lantai semen, kemudian di tutup dengan masingmasing sungkup yang dilengkapi dengan termometer, baterai kering dan kipas angin kecil, begitu juga sungkup tanpa tumbuhan (kontrol). Di setiap sisi sungkup ditutup dengan pasir untuk menghindari udara masuk ke dalam sungkup. Hidupkan kipas angin kecil dalam sungkup serta karet penutup/septum di atas sungkup dibuka selama \pm 2-3 menit, kemudian ditutup kembali. Lakukan pengambilan sampel gas di dalam sungkup melalui septum dengan menggunakan syringe pada periode waktu pukul $06.00,09.00,12.00$ dan 15.00 WIB dengan interval waktu pada menit ke 5, 10, 15, 20, 25 dan 30. Catat data suhu di dalam dan di luar sungkup pada setiap periode waktu pengambilan gas. Pengambilan sampel gas dalam sungkup dilakukan sebanyak 4 kali selama 4 minggu.

Sampel gas dalam syringe dianalisis menggunakan Gas Cromatography di laboratorium Balai Penelitian Lingkungan Pertanian Jakenan Pati, Jawa Tengah. Data hasil analisis gas $\mathrm{CO}_{2}$, dihitung laju serapan gas $\mathrm{CO}_{2}$ dengan menggunakan rumus Khalil, et. al., (1991) :

$$
\mathrm{F}=\frac{\mathrm{dc}}{\mathrm{dt}} \times \frac{\mathrm{Vch}}{\mathrm{Ach}} \times \frac{\mathrm{mW}}{\mathrm{mV}} \times \frac{273,2}{273,2+\mathrm{T}}
$$

Keterangan :

$\mathrm{F} \quad=$ Laju serapan $\mathrm{CO}_{2}$ dalam sungkup $\left(\mathrm{mg} / \mathrm{m}^{2} / \mathrm{menit}\right)$ $\mathrm{dc} / \mathrm{dt}=$ Perbedaan konsentrasi $\mathrm{CO}_{2}$ per satuan waktu (ppm/menit)

$\mathrm{Vch}=$ Volume boks $\left(\mathrm{m}^{3}\right)$

Ach $=$ Luas boks $\left(\mathrm{m}^{2}\right)$

$\mathrm{mW}=$ Berat molekul $\mathrm{CO}_{2}(\mathrm{gr})$

$\mathrm{mV}=$ Volume molekul $\mathrm{CO}_{2}(22,41 \mathrm{~L})$

$\mathrm{T}=$ Suhu rata-rata selama pengambilan contoh gas $\left({ }^{\circ} \mathrm{C}\right)$

Daya Serap $\mathrm{CO}_{2}$ tumbuhan $(\mathrm{Fb})$ merupakan selisih antara laju serapan $\mathrm{CO}_{2}$ dalam sungkup yang berisi tumbuhan dengan laju serapan $\mathrm{CO}_{2}$ dalam sungkup tanpa tumbuhan/kontrol (K), dengan rumus sebagai berikut :

$\mathrm{Fb}=\mathrm{F}-\mathrm{K}$

Keterangan :

$\mathrm{Fb}=$ Daya Serap $\mathrm{CO}_{2}$ tumbuhan $\left(\mathrm{mg} / \mathrm{m}^{2} /\right.$ menit $)$

$\mathrm{F}=$ Laju Serapan $\mathrm{CO}_{2}$ dalam sungkup ( $\left.\mathrm{mg} / \mathrm{m}^{2} / \mathrm{menit}\right)$

$\mathrm{K}$ = Laju Serapan $\mathrm{CO}_{2}$ pada sungkup kontrol/tanpa tumbuhan $\left(\mathrm{mg} / \mathrm{m}^{2} /\right.$ menit $)$

\section{Analisis berat kering, persen dan kadar karbon organik}

Analisis berat kering, persen dan kadar karbon organik masing-masing tumbuhan menggunakan metode gravimetri di laboratorium Jurusan/PS Kehutanan Fakultas Pertanian Universitas Palangka Raya dan dilakukan setelah proses pengukuran serapan gas $\mathrm{CO}_{2}$ selesai dilaksanakan.

\section{HASIL DAN PEMBAHASAN}

\section{Tumbuhan ulayat masyarakat suku dayak}

Masyarakat Suku Dayak memiliki keyakinan tradisional yang didalamnya terkandung sejumlah besar data empiris yang berhubungan dengan fenomena, proses dan sejarah perubahan lingkungan. Salah satu keyakinan tradisional terkait dengan pemahaman terhadap jenis tumbuhan yang masih melekat sampai saat ini adalah penempatan penanaman tumbuhan yang sakral atau lebih dikenal dengan paham "pamali". Paham pamali merupakan pantangan yang harus dihindari dalam menempatkan jenis 
tumbuhan tertentu. Tumbuhan pantangan yang dimaksud adalah yang mengandung getahgetahan dan biasanya dapat tumbuh di sembarang tempat, akan tetapi tidak semua tumbuhan pantangan selalu ada getahnya.

Berdasarkan hasil wawancara dengan responden masyarakat Suku Dayak, beberapa jenis tumbuhan yang memiliki pantangan dalam penempatannya diantaranya Pinang Merah (Cyrtostachys lakka Becc.), Serai (Cymbopogon citratus), Kenanga (Canangium odoratum (Lamk.) Hook. dan Thorms. (Lat.)). Tumbuhan Pinang Merah dan Kenanga tidak boleh ditanam di depan pintu rumah, persisnya pada posisi lurus arah depan pintu tetapi dapat di tanam disamping depan maupun belakang rumah, perkantoran, pertokoan, sekolah dan sepanjang jalan. Hal ini diyakini masyarakat Suku Dayak, jika pantangan tersebut dilanggar dapat menyebabkan penghuni rumah mengalami kesulitan dalam menjalani kehidupannya, seperti susah mendapatkan rezeki dan ketidakharmonisan dalam rumah tangga. Demikian juga untuk tumbuhan Serai yang fungsinya sebagai tumbuhan pangan, tidak boleh ditanam di depan rumah. Jika dilangggar bisa mengakibatkan kehidupan penghuni rumah tidak harmonis dan sebaiknya ditanam di samping dan belakang rumah.

\section{Serapan karbon dioksida tumbuhan ulayat}

Hasil penelitian menunjukkan bahwa tumbuhan ulayat di Kota Palangka Raya memiliki serapan $\mathrm{CO}_{2}$ yang berbeda-beda. Tumbuhan Pinang Merah rata-rata memiliki kemampuan menyerap $\mathrm{CO}_{2}$ paling tinggi dibandingkan Serai dan Kenanga. Berikut data rata-rata serapan $\mathrm{CO}_{2}$ tumbuhan ulayat, seperti pada Gambar 1.

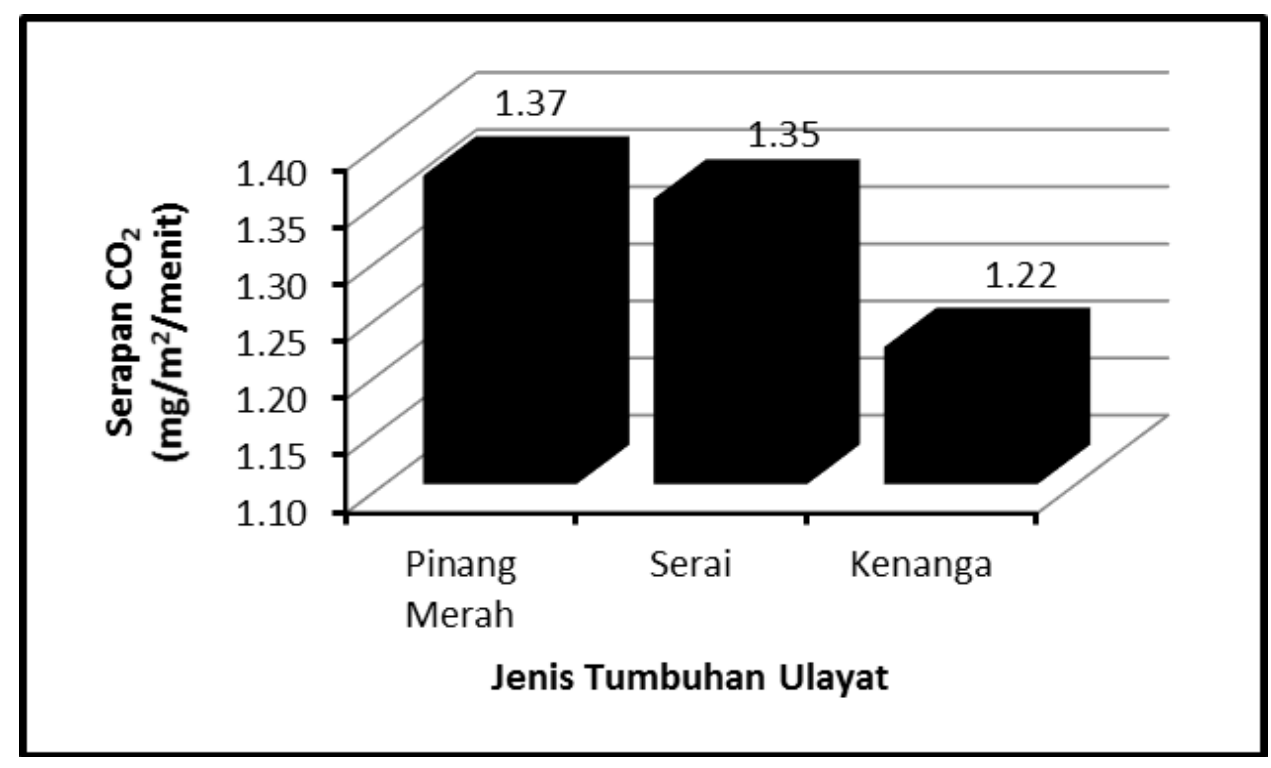

Gambar 1. Rata-rata Serapan $\mathrm{CO}_{2}$ Tumbuhan Ulayat di Kota Palangka Raya

Dwidjoseputro (1980), bahwa kemampuan tumbuhan dalam menyerap $\mathrm{CO}_{2}$ dipengaruhi oleh beberapa faktor seperti suhu, sinar matahari, ketersedian air, luas keseluruhan daun, umur daun dan fase pertumbuhan. Ginting (2009), peningkatan konsentrasi $\mathrm{CO}_{2}$ yang dibarengi dengan intensitas cahaya matahari yang tinggi dapat meningkatkan laju fiksasi $\mathrm{CO}_{2}$ dalam beberapa jenis tumbuhan. Tingginya serapan $\mathrm{CO}_{2}$ tumbuhan Pinang Merah dipengaruhi oleh suhu dan konsentrasi $\mathrm{CO}_{2}$ yang ada di dalam sungkup. Rata-rata suhu pada sungkup yang berisi tumbuhan Pinang Merah lebih tinggi sebesar $36,99{ }^{\circ} \mathrm{C}$ dibandingkan Serai sebesar $36,72{ }^{\circ} \mathrm{C}$ dan Kenanga sebesar $36,56{ }^{\circ} \mathrm{C}$. Peningkatan suhu pada kisaran yang 
normal hanya sedikit berpengaruh terhadap hidrolisis air dan difusi $\mathrm{CO}_{2}$ ke dalam daun, sehingga akan sangat berpengaruh pada reaksi biokimia, fiksasi dan reduksi $\mathrm{CO}_{2}$. Kondisi tersebut mengakibatkan meningkatnya laju fotosintesis, karena suhu mempengaruhi enzim yang bekerja pada proses fotosintesis. Demikian juga, rata-rata besaran konsentrasi $\mathrm{CO}_{2}$ dalam sungkup yang berisi Pinang Merah lebih tinggi sebesar 555,94 ppm dibandingkan Serai sebesar 554,96 ppm dan Kenanga sebesar 549,52 ppm yang berpengaruh terhadap serapan $\mathrm{CO}_{2}$. Mooney dan Ehrelinger (1977), $\mathrm{CO}_{2}$ merupakan bahan utama dalam proses fotosintesis dan kecepatan fotosintesis akan meningkat seiring dengan semakin meningkatnya konsentrasi $\mathrm{CO}_{2}$ intraseluler. Fiksasi $\mathrm{CO}_{2}$ oleh tumbuhan akan semakin meningkat dengan naiknya konsentrasi $\mathrm{CO}_{2}$ di lingkungan sekitar (Wordpress, 2007). Perubahan suhu dan konsentrasi $\mathrm{CO}_{2}$ mempunyai dampak sangat nyata terhadap produktifitas vegetasi dan ekosistem karena sekitar $90 \%$ berat kering/biomasa tumbuhan berasal dari fiksasi $\mathrm{CO}_{2}$ melalui proses fotosintesis (Gardner, et. al., 1991). Proses penyerapan gas $\mathrm{CO}_{2}$ dari udara melalui proses fotosintesis yang kemudian diubah menjadi karbohidrat dan disebarkan ke seluruh organ tumbuhan serta akhirnya ditimbun dalam tubuh tumbuhan. Proses penimbunan karbon dalam tubuh tumbuhan hidup dinamakan proses sekuestrasi (Hairiah, et. al., 2011). Ginting (2009), beberapa respon peningkatan konsentrasi $\mathrm{CO}_{2}$ terhadap tumbuhan diantaranya menstimulir pertumbuhan berupa biomasa, mendorong tanaman untuk mengalami aklimatisasi, penimbunan karbohidrat lebih besar dan meningkatkan ukuran organ namun tidak mempengaruhi perkembangannya. Kondisi tersebut juga terjadi pada tumbuhan Pinang Merah yang memiliki serapan $\mathrm{CO}_{2}$ paling tinggi berpengaruh terhadap jumlah biomasa dan kandungan karbon organik yang tersimpan semakin tinggi, seperti pada Gambar 2.

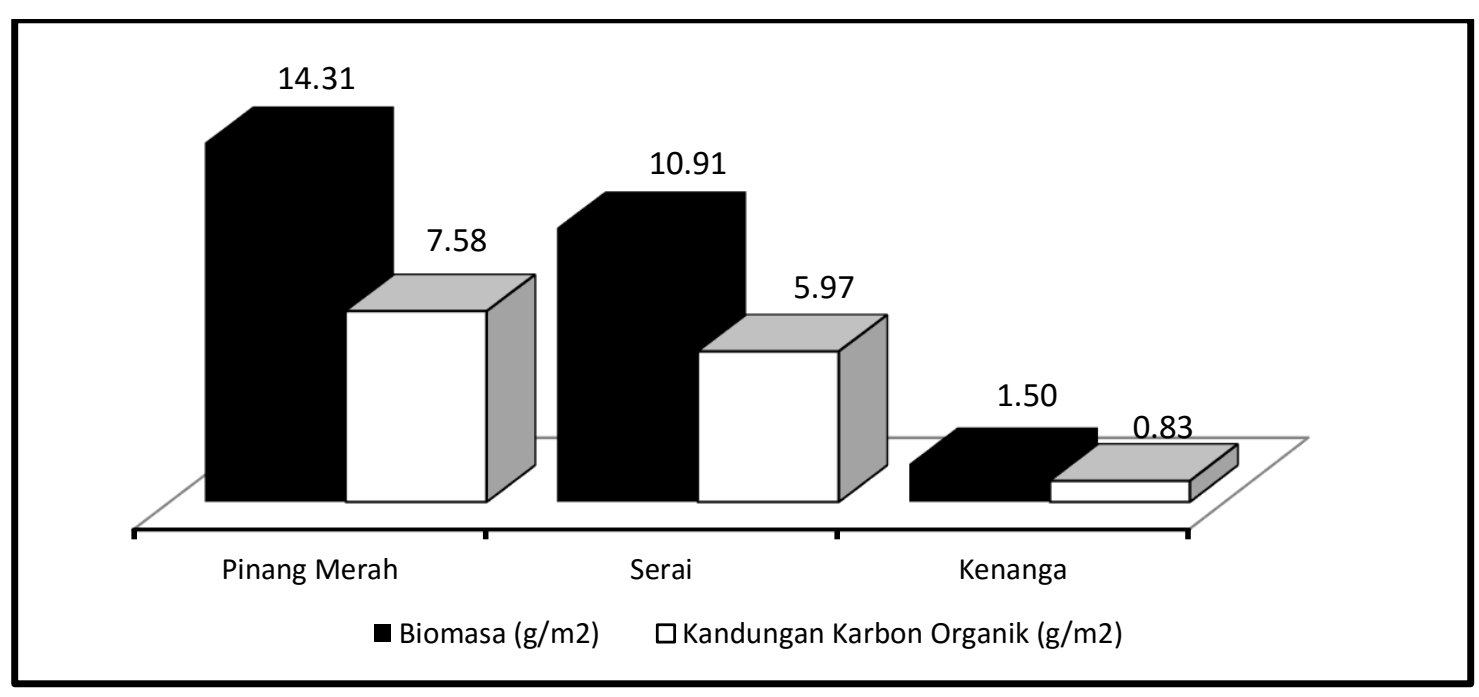

Gambar 2. Rata-rata Biomasa dan Karbon Organik Tumbuhan Ulayat di Kota Palangka Raya

\section{Fluktuasi Serapan Karbon Dioksida Tumbuhan Ulayat}

Fluktuasi laju serapan $\mathrm{CO}_{2}$ tumbuhan Pinang Merah, Serai dan Kenanga pada periode waktu pengamatan pukul 06.00, 09.00, 12.00 dan 15.00 WIB menunjukkan trend yang bervariasi.

Hal tersebut dipengaruhi oleh kondisi sinar matahari dalam memancarkan sinarnya. Fluktuasi serapan $\mathrm{CO}_{2}$ tumbuhan ulayat di Kota Palangka Raya, seperti pada Gambar 3. 


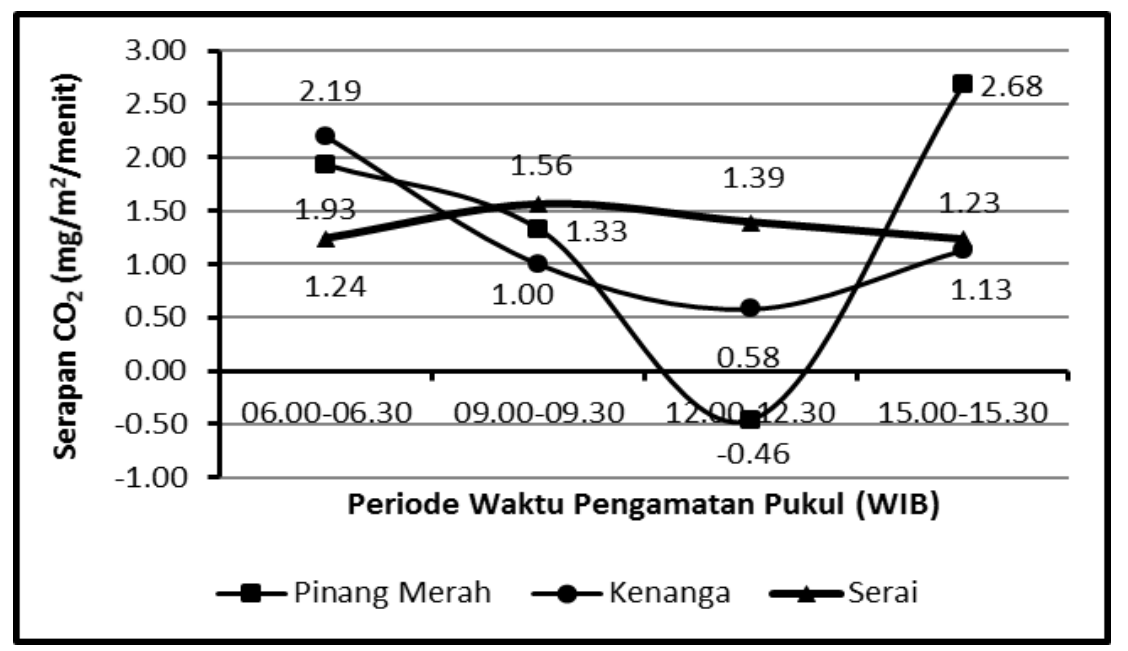

Gambar 3. Fluktuasi Serapan $\mathrm{CO}_{2}$ Tumbuhan Ulayat di Kota Palangka Raya Berdasarkan Periode Waktu Pengamatan

Secara umum rata-rata serapan $\mathrm{CO}_{2}$ tumbuhan Pinang Merah, Serai dan Kenanga pada periode waktu pengamatan pukul $12.00 \mathrm{WIB}$ cenderung mengalami penurunan. Namun pada periode pengamatan pukul 15.00 WIB serapan $\mathrm{CO}_{2}$ tumbuhan Pinang Merah dan Kenanga mengalami peningkatan yang signifikan. Kondisi tersebut disebabkan karena pada periode waktu pengamatan tersebut, cahaya matahari di lokasi penelitian bersinar cukup terik yang berpengaruh terhadap peningkatan suhu maupun konsentrasi $\mathrm{CO}_{2}$. Peningkatan suhu dan konsentrasi $\mathrm{CO}_{2}$ memiliki pengaruh terhadap jumlah fiksasi $\mathrm{CO}_{2}$ yang diserap oleh tumbuhan dan fiksasi $\mathrm{CO}_{2}$ maksimum terjadi pada saat sinar matahari mencapai puncaknya (Gratimah, 2009). Selain itu kondisi tersebut juga mempengaruhi efisiensi proses fotosintesis. Gratimah (2009), efisiensi fotosintesis maksimum akan tercapai apabila intensitas cahaya matahari secara penuh dan hari panjang sehingga peningkatan cahaya matahari secara berangsur-angsur akan meningkatkan fotosintesis sampai tingkat kompensasi cahaya yaitu tingkat cahaya saat pengambilan $\mathrm{CO}_{2}$ sama dengan pengeluaran $\mathrm{CO}_{2}$.

\section{Peran Tumbuhan Ulayat Sebagai Tumbuhan Ruang Terbuka Hijau}

Keberadaan jenis tumbuhan Ruang Terbuka Hijau (RTH) yang ada di Kota Palangka Raya sampai saat ini didominasi oleh jenis Tanjung
(Mimusops elengi L.), Angsana (Pterocarpus indicus) dan Trembesi (Samanea saman (Jacq.) Merr.). Berdasarkan fungsinya ke-3 jenis tumbuhan tersebut merupakan jenis tumbuhan yang memiliki fungsi sebagai tumbuhan pelindung dan cocok tumbuh di Kota Palangka Raya. Namun demikian diperlukan jenis tumbuhan lain yang memiliki fungsi sosial budaya yang terkait dengan masyarakat setempat (Suku Dayak).

Peraturan Menteri PU Nomor 05/PRT/M/2008, bahwa dalam pemilihan jenis tumbuhan untuk RTH perlu memperhatikan 2 hal, yaitu fungsi tumbuhan dan persyaratan penempatannya serta disarankan agar dipilih jenis tumbuhan khas daerah setempat. Fungsi tumbuhan untuk RTH meliputi fungsi utama (intrinsik) atau fungsi ekologis dan fungsi tambahan (ekstrinsik) yang meliputi fungsi sosial budaya, ekonomi dan estetika.

Hasil penelitian ini merekomendasikan bahwa ke-3 jenis tumbuhan ulayat tersebut yaitu Pinang Merah, Serai dan Kenanga perlu mendapatkan perhatian khusus dari Pemerintah Kota Palangka Raya sebagai tumbuhan RTH. Mengingat ke-3 jenis tumbuhan tersebut disamping memiliki fungsi utama juga memiliki fungsi tambahan sebagai tumbuhan sosial budaya, ekonomis dan estetika serta memiliki serapan $\mathrm{CO}_{2}$ yang cukup tinggi yang mampu mengatasi peningkatan gas $\mathrm{CO}_{2}$ di atmosfir. 


\section{KESIMPULAN DAN SARAN}

\section{Kesimpulan}

Jenis tumbuhan yang memiliki nilai-nilai sakral/ulayat bagi masyarakat Suku Dayak di Kota Palangka Raya diantaranya tumbuhan Pinang Merah (Cyrtostachys lakka Becc.), Serai (Cymbopogon citratus) dan Kenanga (Canangium odoratum (Lamk.) Hook. dan Thorms. (Lat.) Serapan $\mathrm{CO}_{2}$ tumbuhan ulayat yaitu tumbuhan Pinang Merah sebesar 1,37 $\mathrm{mg} / \mathrm{m}^{2} /$ menit, Serai sebesar $1,35 \mathrm{mg} / \mathrm{m}^{2} /$ menit dan Kenanga sebesar $1,22 \mathrm{mg} / \mathrm{m}^{2} /$ menit. Fluktuasi serapan $\mathrm{CO}_{2}$ tumbuhan ulayat menunjukkan trend yang bervariasi. Tumbuhan ulayat merupakan tumbuhan yang memiliki fungsi utama (intrinsik) dan fungsi tambahan (ekstrinsik) serta memiliki kemampuan serapan $\mathrm{CO}_{2}$ tinggi yang mampu menekan peningkatan gas $\mathrm{CO}_{2}$ di atmosfir

\section{Saran}

Untuk melengkapi penelitian ini diperlukan kajian proses pelepasan $\mathrm{CO}_{2}$ (proses respirasi) oleh tumbuhan ulayat pada malam hari.

\section{DAFTAR PUSTAKA}

BPS Kota Palangka Raya. 2014. Palangka Raya dalam angka 2014. Badan Pusat Statistik Kota Palangka Raya.

Dwijoseputro, D. 1980. Pengantar fisiologi tumbuhan. PT. Gramedia Jakarta.

Ginting, C. 2009. Interaksi antara peningkatan konsentrasi karbondioksida dan suhu terhadap pertumbuhan tanaman. Buletin Ilmiah INSTIPER, 16(1).

Gratimah, G. 2009. Analisis kebutuhan hutan kota sebagai penyerap gas $\mathrm{CO}_{2}$ antropogenik di pusat Kota Medan. Tesis Fakultas Matematika dan Ilmu Pengetahuan Alam. Universitas Sumatera Utara, Medan.

Hairiah, K., Ekadinata, A., Sari, R.R., Rahayu, S. 2011. Petunjuk praktis pengukuran cadangan karbon dari tingkat lahan ke bentang lahan edisi Ke-2. Word Agroforestry Centre.

Khalil, M. A. K., R. A. Rasmussen and M. X. Wang ang L. Ren. 1991. Methane emission from rice field in China. Enviromental Sciense Technology. 25: p 979-981.

Mooney, H. and J.R. Ehleringer. 1977. Photosynthesis plant ecology. Edited by M. J. Crawley. Blackwell Science, London.

Peraturan Menteri Pekerjaan Umum. 2008. Pedoman penyedian dan pemanfaatan ruang terbuka hijau di kawasan perkotaan.

United Nation Environmental Programe. 2009. Integrated watershed management ecohydrology and phytotechnology.

Wordpress. 2007. Pengaruh kadar gas

karbondiosida pada fotosinteis. http://engineeringbook.files.wordpress.co m/2007/04/ipa_terpadu.pdf. [ 2 September 2013]. 